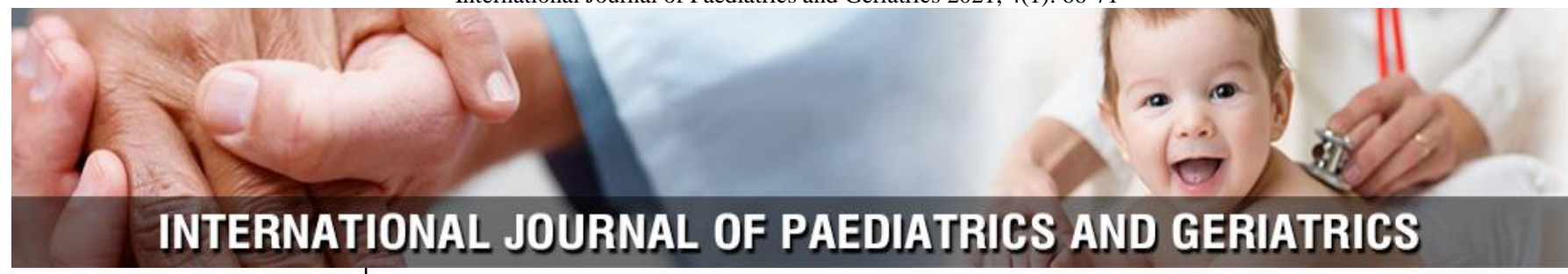

P-ISSN: 2664-3685

E-ISSN: $2664-3693$

www.paediatricjournal.com

IJPG 2021; 4(1): 66-71

Received: 07-01-2021

Accepted: 10-02-2021

Dr. Hajra Tabassum

Assistant Professor,

Department of Paediatrics,

Shadan Institute of Medical

Sciences, Peerancheru,

Hyderabad, Telangana, India

\section{A study of serum iron and zinc levels in children with malaria}

\section{Dr. Hajra Tabassum}

DOI: $\underline{\text { https://doi.org/10.33545/26643685.2021.v4.i1b.130 }}$

\begin{abstract}
Background: Malaria is a disease of global importance and afflicts more than ninety countries and territories in the tropical and subtropical region. Metals such as iron and zinc are essential for different biological functions in human beings and are co-factors in most of the enzymes. However, data about significant variation of these micronutrients during infections in developing countries where we encounter malnutrition and infection problem together are limited.

Objectives: This study was undertaken to quantify the serum levels of iron and zinc in malaria infected children and to compare it with that of controls and to correlate the levels with type of malaria, and outcome of illness.

Methods: Thirty cases of proven malaria and 30 age and sex matched controls were recruited during the study period. Blood samples were obtained from each patients and controls, centrifuged and serum was analyzed for estimation of iron and zinc using spectrophotometer.

Results: Mean serum iron among 30 cases was found to be $88.47 \mu \mathrm{g} / \mathrm{dl}$, when compared to controls $(97.47 \mu \mathrm{g} / \mathrm{dl})$, it was low. The mean serum zinc levels among 30 cases was $42.67 \mu \mathrm{g} / \mathrm{dl}$, which is statistically lower than among controls $57.43 \mu \mathrm{g} / \mathrm{dl}$. There was no difference between the types of malaria.

Conclusion: The present study showed that there is significant reduction in the serum levels of iron and zinc in children admitted with malaria. It may suggest that the decreased levels of iron and zinc can be rectified by supplementing these metals in therapy. Further detailed studies are needed in this aspect.
\end{abstract}

Keywords: iron, malaria, socio economic status, spectrophotometer, zinc

\section{Introduction}

Malaria is an important public health problem in developing countries like India. Plasmodium ( $\mathrm{Pl})$ falciparum (53\%), Pl. vivax (47\%) are the pathogenic agents of malaria and are the major causes of morbidity and mortality of children under five years of age in India ${ }^{[1]}$. It was relatively free from malaria until early 1990 with only sporadic case reports. But since 1990, with a sudden spurt in industrialisation and construction activities, malaria has made a dramatic entry here. Most of these cases in have occurred in the city of Hyderabadits head quarters. It has been observed that the incidence of malaria increases with the onset of the monsoon (June to October), when the water logging helps mosquito breeding and thus transmission of the disease ${ }^{[2]}$.

Recently, there has been increase in the resistance to the commonly used anti malarial drugs and insecticides ${ }^{[3]}$. The increase in morbidity and mortality prompts us to study the factors that could lead to malaria infection.

Metals such as zinc and iron are essential for different biological functions in human beings and are co-factors in most of the enzymes. Sufficient zinc supply is important for maintaining immune system function. Individuals exhibiting a zinc deficiency are more prone to various infectious diseases, such as pneumonia, diarrhea, and (in children) malaria. Some authors have associated malaria acquisition and its severity to the concentrations of micronutrients in children, the protection against acute infection through a moderate deficiency in iron ${ }^{[4]}$, the reduction of risk of fever and clinical malaria episodes through a zinc supplementation ${ }^{[5,6]}$. There are a few possible reasons by which iron status influences succeptibility to malaria like, iron supplementation might enhance susceptibility by stimulating erythropoiesis because there is evidence that parasites have a preference for reticulocytes (plasmodium vivax) ${ }^{[7]}$. Also zinc protoporphyrin, a product of iron deficient erythropoiesis has anti malarial action ${ }^{[8]}$. 
However, data about significant variation of these micronutrients during infections in developing countries where we encounter malnutrition and infection problems together are limited. Hence this study was taken to quantify the levels of iron and zinc, two important nutrients in children affected with malaria.

\section{Objectives of the present study}

1. To quantify the serum levels of iron and zinc in malaria infected children and to compare it with that of controls.

2. To correlate the levels with type of malaria.

3. To correlate the levels with the severity of malaria and outcome of illness.

\section{Materials and Methods}

Study group:

Thirty children aged 1 to 15 years, admitted in Shadan Institute of Medical Sciences with history of fever and malarial parasite flourescent test (MPFT) positive and smear positive were included in the study

Type of study: case control study

Sample size: 30 study group and 30 controls

\section{Method of Collection of Data}

Thirty cases of proven malaria and 30 age and sex matched controls were recruited during the study period. Parents were explained about the objective of the study, and after obtaining written consent from one of the parents, the children were included in the study. A detailed history and examination findings were entered in a predesigned proforma. Severity of malaria was assessed as per WHO classification. Child was followed up daily till discharge and upto one month after that and the outcome was recorded.

Controls were selected from (a) children who came to out patient department for immunization, (b) clinically normal siblings of sick children and from (c) clinically normal children from school camps where blood samples were routinely taken for blood grouping, after explaining about the objective of the study in their local language and obtaining consent from parent/ guardian. Local anaesthetic cream was applied over the site of collection of sample to relieve pain. Children if found deficient of these micronutrients were corrected with appropriate supplementation.

\section{Inclusion Criteria}

Group 1(Study group): Children aged 1-15 years, admitted with fever and malaria test positive.

\section{Group 2(Control group): Children aged 1-15 years} (apparently normal- controls)

\section{Exclusion Criteria}

1. Children $<1$ years and $>15$ years

2. Children with debilitating illnesses

3. Children with coexisting other illnesses like diarrhea, pneumonia.

4. Children who have received zinc, multivitamin preparations containing zinc or iron supplementation in the past one month.

\section{Collection of Samples}

Blood samples were collected with aseptic precautions as per requirement and processed accordingly. All relevant investigations were done as per need.

\section{Methodology}

1. MPFT was done by using Quantitative Buffy Coat (QBC) flourescent test and was reconfirmed with thick and thin smear.

2. Serum iron estimation was done in COBAS 6000 by using spectrophotometric method using ferrozine reagent.

3. Serum zinc was estimated by calorimetric method in an absorption spectrophotometer using nitro PAPS reagent.

\section{Statistical Analysis}

The collected data were analysed by mean, standard deviation, t-test, chi- square and by Karl Pearson's correlation coefficient. $\mathrm{P}$ value $\leq 0.05$ was considered significant.

\section{Results}

Thirty children admitted with malaria infection were taken as study group and 30 normal healthy children were taken as controls.

\section{Age Distribution}

Out of the 30 cases, $36.7 \%$ were within the age group of 1 to 5 years, $16.7 \%$ were within 6 to 10 years and $46.7 \%$ were between 11-15 years. Out of the 30 controls, $23.3 \%$ were within 1 to 5 years, $40 \%$ were within $6-10$ years, $36.7 \%$ were within 11-15 years. (Table 1).

Table 1: Age Distribution

\begin{tabular}{|c|c|c|c|c|}
\hline & \multicolumn{2}{|c|}{ Group } & \multirow[b]{2}{*}{ Total } \\
\hline & & Cases & Controls & \\
\hline \multirow{3}{*}{ Age } & $1-5$ years & $\begin{array}{c}11 \\
36.7 \%\end{array}$ & $\begin{array}{c}7 \\
23.3 \%\end{array}$ & $\begin{array}{c}18 \\
30.0 \%\end{array}$ \\
\hline & $6-10$ years & $\begin{array}{c}5 \\
16.7 \%\end{array}$ & $\begin{array}{c}12 \\
40.0 \%\end{array}$ & $\begin{array}{c}17 \\
28.3 \%\end{array}$ \\
\hline & $11-15$ years & $\begin{array}{c}14 \\
46.7 \%\end{array}$ & $\begin{array}{c}11 \\
36.7 \%\end{array}$ & $\begin{array}{c}25 \\
41.7 \%\end{array}$ \\
\hline \multicolumn{2}{|r|}{ Total } & $\begin{array}{c}30 \\
100.0 \%\end{array}$ & $\begin{array}{c}30 \\
100.0 \%\end{array}$ & $\begin{array}{c}60 \\
100.0 \%\end{array}$ \\
\hline
\end{tabular}

\section{Sex distribution:}

Out of the 30 cases, $66.7 \%(n-=20)$ were males and $33.3 \%$ $(n=10)$ were females, whereas in the control group $60 \%$ $(n=18)$ were male and $40 \%$ were females (Table2)

Table 2: Sex Distribution

\begin{tabular}{|c|c|c|c|c|}
\hline & \multicolumn{2}{|c|}{ Group } & \multirow[b]{2}{*}{ Total } \\
\hline & & Cases & Controls & \\
\hline \multirow{2}{*}{ Sex } & Male & $\begin{array}{c}20 \\
66.7 \%\end{array}$ & $\begin{array}{c}18 \\
60.0 \%\end{array}$ & $\begin{array}{c}38 \\
63.3 \%\end{array}$ \\
\hline & Female & $\begin{array}{c}10 \\
33.3 \% \\
\end{array}$ & $\begin{array}{c}12 \\
40.0 \% \\
\end{array}$ & $\begin{array}{c}22 \\
36.7 \% \\
\end{array}$ \\
\hline \multicolumn{2}{|c|}{ Total } & $\begin{array}{c}30 \\
100.0 \%\end{array}$ & $\begin{array}{c}30 \\
100.0 \%\end{array}$ & $\begin{array}{c}60 \\
100.0 \%\end{array}$ \\
\hline
\end{tabular}

\section{Socio economic status}

Among 30 malaria cases, majority (50\%) were from class 3 socioeconomic status, $36.7 \%$ were from class 2 and the rest 
from class 4. Among controls, majority were from class $3(63.3 \%), 30 \%$ were from class 2 and rest from class 4 . (Table 3)

Table 3: Socioeconomic status

\begin{tabular}{|c|c|c|c|c|}
\hline & \multicolumn{2}{|c|}{ Group } & \multirow[b]{2}{*}{ Total } \\
\hline & & Cases & Controls & \\
\hline \multirow{3}{*}{$\begin{array}{c}\text { Socio economic } \\
\text { status }\end{array}$} & Class 2 & $\begin{array}{c}11 \\
36.7 \%\end{array}$ & $\begin{array}{c}9 \\
30.0 \%\end{array}$ & $\begin{array}{c}20 \\
33.3 \%\end{array}$ \\
\hline & Class 3 & $\begin{array}{c}15 \\
50.0 \% \\
\end{array}$ & $\begin{array}{c}19 \\
63.3 \% \\
\end{array}$ & $\begin{array}{c}34 \\
56.7 \% \\
\end{array}$ \\
\hline & Class 4 & $\begin{array}{c}4 \\
13.3 \%\end{array}$ & $\begin{array}{c}2 \\
6.7 \%\end{array}$ & $\begin{array}{c}6 \\
10.0 \%\end{array}$ \\
\hline \multicolumn{2}{|l|}{ Total } & $\begin{array}{c}30 \\
100.0 \%\end{array}$ & $\begin{array}{c}30 \\
100.0 \%\end{array}$ & $\begin{array}{c}60 \\
100.0 \%\end{array}$ \\
\hline
\end{tabular}

\section{Clinical symptoms}

The presenting symptoms in 30 children have been summarised in the below diagram. All patients were febrile at the time of presentation. Vomiting was one of the frequent symptoms after fever. It was seen in $53.3 \%$ of the total cases. Headache was the third common presenting symptom along with fever. It was noted in $46.7 \%$ of patients.

\section{Clinical signs}

Pallor was noted in $33 \%$ of the total cases. Icterus was noted in $2(6.7 \%)$ patients. Out of thirty cases, twenty one had only splenomegaly, 2 cases had both hepatomegaly and splenomegaly.

\section{Hemoglobin}

Out of 30 patients 6 patients had $\mathrm{Hb}$ less than $10 \mathrm{gm} / \mathrm{dl}$. Out of which 3 cases had $\mathrm{Hb}$ between $7-10 \mathrm{gm} / \mathrm{dl}$ and three patients had $\mathrm{Hb}<7 \mathrm{gm} / \mathrm{dl}$. Mean $\mathrm{Hb}$ in our study was $11.07 \pm 2.15 \mathrm{~g} / \mathrm{dl}$. $\mathrm{Hb}<7 \mathrm{gm} \%$ was seen only with falciparum and mixed infection.

\section{Thrombocytopenia}

In our study thrombocytopenia was observed in $80 \%$ (24 out of 30) of the patients. Out of these 30 patients, 2 patients had severe thrombocytopenia $(<50,000 /$ comm.), 15 patients had moderate thrombocytopenia (platelet count between 50000 and 100000) and 7 patients had mild thrombocytopenia (platelet count between 100000 and 150000). Severe thrombocytopenia was documented in one case of vivax and in one case of mixed infection. (Table: 4 \& Figures: 12-15)

Table 4: Platelet Count

\begin{tabular}{|c|c|c|c|}
\hline Platelet Count (per cubic mm) & Vivax & Falciparum & Mixed \\
\hline$>1.5$ Lakh & 5 & 1 & 0 \\
\hline 1-1.5 Lakh & 5 & 2 & 0 \\
\hline $50,000-1$ Lakh & 11 & 0 & 4 \\
\hline$<50,000$ & 1 & 0 & 1 \\
\hline
\end{tabular}

\section{Iron}

The mean serum iron levels among 30 cases was 88.47 $(\mu \mathrm{g} / \mathrm{dl})$, and among controls were found to be $97.47(\mu \mathrm{g} / \mathrm{dl})$. The difference between them is statistically significant. (Table: 5)

Table 5: Mean iron levels

\begin{tabular}{|c|c|c|c|c|c|c|c|c|}
\hline & \multirow{2}{*}{$\mathbf{N}$} & \multirow{2}{*}{ Mean } & \multirow{2}{*}{$\begin{array}{c}\text { Std. } \\
\text { Deviation }\end{array}$} & \multirow{2}{*}{ Median(IQR) } & \multicolumn{2}{|c|}{ 95\% Confidence Interval for Mean } & \multirow{2}{*}{$\begin{array}{c}\text { Mann whitney test } \\
\text { Z value }\end{array}$} & \multirow[b]{2}{*}{$\mathbf{p}$} \\
\hline & & & & & Lower Bound & Upper Bound & & \\
\hline Cases & 30 & 88.47 & 77.439 & $62(33-112)$ & 59.55 & 117.38 & \multirow{2}{*}{2.181} & \multirow{2}{*}{$0.029 *$} \\
\hline Contr ols & 30 & 97.47 & 22.928 & $92(82.25-104.25)$ & 88.91 & 106.03 & & \\
\hline
\end{tabular}

\section{Zinc}

The mean serum zinc levels among 30 cases was $42.67(\mu \mathrm{g} / \mathrm{dl})$, and among controls were found to be $57.43(\mu \mathrm{g} / \mathrm{dl})$. The difference between them is statistically significant. (Table: 6)

Table 6: Mean zinc

\begin{tabular}{|c|c|c|c|c|c|c|c|}
\hline & \multirow{2}{*}{$\mathbf{N}$} & \multirow{2}{*}{$\operatorname{Mean}(\mu \mathrm{g} / \mathrm{dl})$} & \multirow{2}{*}{$\begin{array}{c}\text { Std. } \\
\text { Deviation }\end{array}$} & \multicolumn{2}{|c|}{ 95\% Confidence Interval for Mean } & \multirow[b]{2}{*}{ t value } & \multirow[b]{2}{*}{$\mathbf{p}$} \\
\hline & & & & Lower Bound & Upper Bound & & \\
\hline Cases & 30 & 42.67 & 6.065 & 40.40 & 44.93 & \multirow{2}{*}{11.216} & \multirow{2}{*}{$\mathrm{p}<0.001 *$} \\
\hline Controls & 30 & 57.43 & 3.901 & 55.98 & 58.89 & & \\
\hline Total & 60 & 50.05 & 9.000 & 47.73 & 52.37 & & \\
\hline
\end{tabular}

\section{Duration of hospital stay}

Out of 30 patients, majority (25 cases) had a hospital stay of 3-5 days, only 2 had a stay of 6 days and 3 children were admitted for 2 days. The two cases who stayed for 6 days had mixed malaria. (Table: 7)

Table 7: Duration of hospital stay

\begin{tabular}{|c|c|c|c|}
\hline & Vivax & Falciparum & Mixed \\
\hline$<3$ days & 3 & 0 & 0 \\
\hline 3-5 days & 19 & 3 & 3 \\
\hline$>5$ days & 0 & 0 & 2 \\
\hline
\end{tabular}

\section{Comparision of zinc and iron with type of malaria}

The mean serum zinc levels among 30 cases was $42.67(\mu \mathrm{g} / \mathrm{dl})$, and doesn't vary with the type of malaria which is evident from the table below (Table: 8 ), whereas there is significant variation in the mean iron levels in different types of malaria, but not statistically significant.

Table 8: Comparision of zinc and iron with type of Malaria

\begin{tabular}{|c|c|c|c|c|c|}
\hline & Type & $\mathbf{n}$ & Mean & Std deviation & P value \\
\hline \multirow{3}{*}{ Zinc } & vivax & 22 & 42.82 & 5.80 & \multirow{3}{*}{0.864} \\
\hline & falciparum & 3 & 42.67 & 9.87 & \\
\hline & mixed & 5 & 42.00 & 6.36 & \\
\hline \multirow{3}{*}{ Iron } & vivax & 22 & 65.41 & 45.13 & \multirow{3}{*}{0.147} \\
\hline & falciparum & 3 & 131.67 & 121.71 & \\
\hline & mixed & 5 & 164 & 117.99 & \\
\hline
\end{tabular}

\section{Correlation of iron and zinc with hospital stay}

In relation to the duration of hospital stay with the mean serum levels of zinc and iron, there were no statistically significant difference except for higher levels of serum iron 
in patients who stayed for more than 5 days, but there were only 2 patients in that group. (Table: 9)

Table 9: Correlation of iron and zinc with hospital stay

\begin{tabular}{|c|c|c|}
\hline Duration of hospital stay & Mean iron $(\boldsymbol{\mu g} / \mathbf{d l})$ & Mean zinc $(\boldsymbol{\mu g} / \mathbf{d l})$ \\
\hline$<3$ days & 64.5 & 45 \\
\hline 3-5 days & 78.8 & 42.4 \\
\hline$>5$ days & 237 & 43.5 \\
\hline
\end{tabular}

\section{Severity of malaria}

There were no cases of severe malaria in the study population.

\section{Outcome of illness}

All cases admitted with malaria improved with treatment without any residual complications.

\section{Discussion}

Malaria is a public health problem in several parts of the country. About $95 \%$ population in the country resides in malaria endemic areas and $80 \%$ of malaria reported in the country is confined to areas consisting $20 \%$ of population residing in tribal, hilly, difficult and inaccessible areas. According to world malaria report 2014, 53\% of malaria cases were caused by P.falciparum and $47 \%$ by P.vivax ${ }^{[1]}$. There were 440 reported deaths in 2014 due to malaria. India contributes $77 \%$ of the total malaria in Southeast Asia and about $95 \%$ of the population of moderate to high risk of malaria in SEA Region is living in India. Though we are familiar with various presentations and complications of malaria, the effect of trace elements like iron and zinc are not understood. There are only few studies of this kind, which were also done in abroad. Our study is a hospital based comparative study of serum iron and zinc levels in children with malaria and matched controls.

\section{Sex distribution}

In our study the male to female ratio was 2:1 compared to Yadav D et al. ${ }^{[9]}$ where male to female ratio was 2.88:1. In their study high male predominance was attributed to higher health seeking behavior for male children.

\section{Age group}

Children between 11-15 years of age constituted higher number in our study. This may be due to increased exposure to mosquito bites outdoors compared to younger children. Jasani JH et al. ${ }^{[10]}$ observed similar results in their study.

\section{Clinical features}

Presenting symptoms of our study showed similarity to the presenting symptoms of the study group of Sowunmi et al. ${ }^{[11]}$ Percentage of children having vomiting, headache and pain abdomen in our study was comparable with studies done by Sowunmi A and Rasheed A et al. ${ }^{[12]}$ but their studies included only P.falciparum.

\section{Clinical signs}

Commonest clinical findings in our study were splenomegaly and pallor. Incidence of pallor was $34 \%$ in our study in comparison to $75 \%$ in study carried out by Malhotra OP et al. ${ }^{[13]}$ Splenomegaly was seen in $70 \%$ of the patients in our study. Similar rate was observed in study by Rasheed A et al. ${ }^{[12]}$ in a study from Pakistan. Hepatomegaly was noted in $7 \%$ of the patients in the present study. Study by Rasheed A et al. ${ }^{[12]}$ had shown a similar incidence of hepatomegaly $(6.3 \%)$ in their work. Sowunmi A has reported that hepatomegaly was more common than splenomegaly in acute falciparum infection in children. This observation is contrary to our findings wherein splenomegaly was more common. The clinical findings in vivax, falciparum and mixed infections were more or less similar. There was no statistically significant difference in clinical presentation of various types of malaria.

\section{Types of Malaria}

In the present study vivax malaria constituted was $73 \%$, falciparum was $10 \%$ and mixed infection constituted $17 \%$. In a study by Shetty $\mathrm{G}$ et al. ${ }^{[14]}$ had similar results compare to our study. Jadav UM et al. ${ }^{[15]}$ had similar incidence of vivax malaria in their studies. Rasheed A et al. ${ }^{[12]}$ had higher incidence of falciparum infection, which was attributed to higher incidence of falciparum infection in the area in which study was conducted. Study by Faseela TS ${ }^{[16]}$ et al. observed higher incidence of mixed infection like our study, which was attributed to endemicity for malaria in that area. From these observations we can conclude that the incidence of particular species varies with geographical area. This area is endemic for vivax infection and hence the higher incidence of vivax infection in our study.

\section{Anemia}

Mean hemoglobin in our study was $11.07 \pm 2.15 \mathrm{gm} \%$, which is less compare to Rasheed A et al. ${ }^{[12]}$ study, where mean $\mathrm{Hb}$ was $12.87 \pm 1.88 \mathrm{gm} \%$. Marsh K et al. ${ }^{[17]}$ had reported an incidence of $17 \%$ of severe anemia in his study group, which is higher than what we observed $(10 \%)$. Twenty percent of the study population had $\mathrm{Hb}$ less than $10 \mathrm{gm} \%$, only $10 \%$ had $\mathrm{Hb}$ less than $7 \mathrm{gm} \%$. The causes for anemia in malaria are multifactorial. Following are possible causes for anemia in malaria.

- Extravascular clearance and/or intravascular destruction of infected and uninfected RBCs

- Activation of the monocyte / macrophage system

- Suppression of erythropoiesis along with dyserythropoiesis ${ }^{[25]}$

\section{Thrombocytopenia}

In our study thrombocytopenia was observed in $80 \%$ of the patients. $23 \%$ had mild thrombocytopenia, 50\% had moderate and $7 \%$ had severe degree thrombocytopenia. Shetty $\mathrm{G}$ et al. ${ }^{[14]}$ and Jamal et al. ${ }^{[18]}$ had similar results in their work, but few studies ${ }^{[19]}$ have reported slightly lower incidence of thrombocytopenia like $40 \%$ and $58.97 \%$ respectively. The causes of thrombocytopenia in acute malaria are poorly understood. Experimental data and clinical studies have successively emphasized the role of immune factors and the destruction or sequestration of platelets ${ }^{[14]}$. It is a general consensus that thrombocytopenia is very common in malaria and it is usually believed to be more common in falciparum malaria. Contrary to the popular belief, vivax infection can give rise to thrombocytopenia as was seen in our study, which was noticed by earlier few studies also ${ }^{[14]}$.

\section{Iron status}

In our study, the mean serum iron level was $88.47 \mu \mathrm{g} / \mathrm{dl}$ for malaria cases, which was low compared to $97.47 \mu \mathrm{g} / \mathrm{dl}$ for 
controls, and is statistically significant. In a study done by Baloch $\mathrm{S}$ et al. ${ }^{[20]}$, the mean iron in study group were significantly reduced compared to that of controls. Similar results were obtained by M'boh et al. ${ }^{[21]}$ There is variation noted in mean serum iron levels in different types of malaria, but it is not statistically significant because of very small sample size in falciparum and mixed malaria group. Similar results obtained for its correlation with duration of hospital stay. Whether lower iron made them susceptible to malaria or iron level is decreased due to malaria is not clear. Probably a prospective study involving large population can answer this.

\section{Zinc status}

In our study, the mean serum zinc obtained was $42.67 \mu \mathrm{g} / \mathrm{dl}$ for cases, which was low compared to $57.43 \mu \mathrm{g} / \mathrm{dl}$ for controls, which is statistically significant. In a study done by M'boh et al. ${ }^{[21]}$, the mean zinc was 21 for cases and 60 for controls, which was comparable with our study. Baloch $\mathrm{S}$ et al. ${ }^{[20]}$ also showed the same results. There is no significant variation in the levels of zinc with the type of malaria or with the duration of hospital stay. Since there were no cases of severe malaria in the study population, zinc status in severe malaria could not be studied. However literature says that with severe malaria there is marked decrease in zinc levels.

\section{Limitations of the study}

Smaller sample size and lack of severe malaria cases were the major limitations of this study.

\section{Conclusion}

The present study showed there is significant reduction in the serum levels of iron and zinc in children admitted with malaria, which shows there is a damageable effect on trace elements by malaria. It may suggest that the decreased levels of iron and zinc can be restored by supplementing these metals in therapy. In order to establish true picture of the incidence, prevalence and causes of zinc, iron deficiency, correlation with severity requires further extensive clinical studies and research.

\section{Acknowledgment}

The author is thankful to Department of Paediatrics for providing all the facilitates to carry out this work.

\section{Conflict of Interest}

None

\section{Financial Support}

Nil

\section{References}

1. Malaria fact sheet April 2015 [online] Available from: URL: http://www.who.int/mediacentre/factsheets/fs094/en/ [Accessed on May 05, 2015].

2. Kakkilaya BS, Malaria in India [internet] 2012 [updated 2012 April12; accessed on 2013 August 06]. Available from http://www.malariasitecom/malaria /MalariaInIndia.htm

3. Joseph DA, Brice BK, William Y, Lacina O, Felix Y, Hugues A et al. In vitro susceptibility of Plasmodium falciparum isolates from Abidjan (Ivory Coast) to artemisinin, chloroquine, dihydroartemisinin and pyronaridine, Tanzan J Health Res 2010;1:12(1).

4. Nyakeriga AM, Troye-Blomberg M, Dorfman JR, Alexander ND, Back R, Kortok $\mathrm{M}$ et al. Iron Deficiency and Malaria among Children Living on the Coast of Kenya, J Infect Dis 2004;190:439-47.

5. Seyrek A, Kocyigit A, Erel O. Essential trace elements selenium, zinc, copper, and iron concentrations and their related acute-phase proteins in patients with vivax malaria. Biological Trace Element Research 2005;106(2):107-15

6. Zeba AN, Sorgho H, Rouamba N, Zongo I, Rouamba J, Guiguemde RT et al. Major reduction of malaria morbidity with combined vitamin $\mathrm{A}$ and zinc supplementation in young children in Burkina Faso: a randomized double blind trial. Nutrition Journal 2008;7:7.

7. Prentice AM. Iron Metabolism, Malaria, and Other Infections: What is all the fuss about. J Nutr 2008;138(12):2537-2541

8. Iyer JK, Shi L, Shankar AH, Sullivan DA. Zinc protoporphyrin IX binds heme crystals to inhibit the process of crystallization in Plasmodium falciparum. Mol Med 2003;9:175-82.

9. Makino T. A sensitive direct colorimetric assay of serum zinc using Nitro PAPS and microwell plates. Clin Chim ACTA 1991;197:209-220

10. Jasani JH, Sancheti SM, Gheewala BS, Bhuva KV, Doctor VS, Vacchani AB et al. Association of the electrolyte disturbances $(\mathrm{Na}+, \mathrm{K}+)$ with the type and severity of the malarial parasitic infection. J Clin Diagn Res 2012;6(4):678-681.

11. Sowunmi A. Renal function in acute falciparum malaria. Archives of Disease in Childhood 1996;74(4):293-298.

12. Rasheed A, Saeed S, Khan SA. Clinical and laboratory findings in acute malaria caused by various plasmodium species. J Pak Med Assoc 2009;59(4):2203.

13. Malhotra OP, Bhatia V, Samanthray JC, Saxena R. A study of clinical and Haematological manifestation of malaria. Ind J Haematology \& Blood Transfusion 1997; 15:40-43

14. Shetty G, Avabratha KS, Gonsalves S, Dany A, Rai BS. Thrombocytopenia in children with malaria- A study from coastal Karnataka, India. Asian Pacific Journal of Tropical Disease 2012;2(2):107-109

15. Jadhav UM, Patkar VS, Kadam NN. Thrombocytopenia in malaria - correlation with type and severity of malaria. J Assoc Physicians India 2004;52:615-8.

16. Faseela TS, Ronald AR, Anitha KB, Chaithra SM, Yashwanth R. Diagnostic value of platelet count in malaria. J Clin Diagn Res 2011;5(3):464-466.

17. Marsh K, Forster D, Waruiru C, Mwangi I, Winstanley $\mathrm{M}$, Marsh $\mathrm{V}$ et al. Indicators of Life-Threatening Malaria in African Children. New England Journal of Medicine 1995;332(21):1399-1404.

18. Jamal A, Memon IA, Latif F. The association of Plasmodium vivax malaria with thrombocytopenia in febrile children. Pak Paediatr J 2007;31(2):85-89.

19. Rodriguez-Morales A. Anemia and thrombocytopenia in children with Plasmodium vivax malaria. J Trop Pediatr 2006;52(1):49-51. 
20. Baloch S, Memon SA, Gachal GS, Baloch M. Determination of Trace Metals Abnormalities in Patients with Vivax Malaria. Iranian J Parasitol 2011;6(2):54-59

21. M'boh MG, Yapi FH, Ahiboh HT, Yapo A, Bla BK, Djaman DA. The effect of falciparum malaria infection on the quantity of trace elements (iron, copper, zinc) in the blood in children of Cote d'Ivoire. Agric. Biol. J. North America 2010;1(4):565-570. 